\title{
THE CEREBRAL BLOOD FLOW IN MALE SUBJECTS AS MEASURED \\ BY THE NITROUS OXIDE TECHNIQUE. NORMAL VALUES FOR BLOOD FLOW, OXYGEN UTILIZATION, GLUCOSE UTILIZATION, AND PERIPHERAL RESISTANCE, WITH OBSERVATIONS ON THE EFFECT OF TILTING AND ANXIETY ${ }^{1}$
}

\author{
By PERITZ SCHEINBERG ${ }^{2}$ AND EUGENE A. STEAD, JR.
}

\author{
(From the Department of Medicine, Duke University School of Medicine, Durham, \\ North Carolina)
}

(Received for publication March 18, 1949)

The nitrous oxide technique for the semiquantitative measurement of cerebral blood flow devised by Kety and Schmidt $(1,2)$ has made it desirable to restudy the cerebral circulation in man in various physiologic states. By measuring arterio-internal jugular differences of oxygen and glucose, the relation between changes in cerebral blood flow and cerebral metabolism can be observed. The purpose of this report is to record our findings in the use of the nitrous oxide technique in 33 observations on 20 normal young men; in the comparison of certain cerebral metabolic functions on 14 normal young men in the supine and erect postures; and in observations on the effects of apprehension on the cerebral circulation.

\section{METHOD}

Seventeen of the 20 subjects were normal, male medical students; the other three (W. Mc., D. M., and R. H. in Table I) were hospital patients who showed no evidence of disease. All the subjects were studied in the fasting state. Following local procainization, a 19 gauge, $6.5 \mathrm{~cm}$. needle was inserted into the right internal jugular bulb in the manner described by Myerson (3), and an arterial needle was inserted in the right femoral artery. Following this the patient was allowed to lie quietly for 40 to 50 minutes before the procedure was continued.

The essential nature of the experiments ascribed in all theoretical details to the nitrous oxide method described by Kety and Schmidt $(1,2)$, but the mean arterio-venous nitrous oxide difference for the 10 minute period was measured differently. Instead of drawing five separate, simultaneous samples from the artery and vein for the plotting of the nitrous oxide curves, simultaneous continuous samples (called integrated samples) were drawn from the artery and vein into heparinized, oiled syringes

1 This work was supported by a grant from the Anna M. Hanes Research Fund.

2 Holder of American College of Physicians Clinical Fellowship 1948-1949. at the rate of $0.25 \mathrm{ml}$. every 7.5 seconds for the entire 10 minute period of gas inhalation. That this can be done accurately was demonstrated by drawing similar integrated samples simultaneously from the two femoral arteries in four subjects while the subject breathed the nitrous oxide mixture; the mean nitrous oxide contents of these samples were identical in each subject. When the collection of the integrated samples is complete, the gas is continued for another 20 seconds while simultaneous samples of $6 \mathrm{ml}$. each are drawn from the artery and vein. These are used for the determination of the level of the arterial and venous nitrous oxide contents, respectively, at the end of 10 minutes of inhalation. The venous sample represents the cerebral nitrous oxide concentration per gram of brain, since after 10 minutes the internal jugular blood and brain nitrous oxide should be in equilibrium and the solubility coefficient for nitrous oxide between blood and brain has been shown to be about 1.0 (4). The arterial sample serves as an internal check on the accuracy of the procedure. It should closely agree with the venous sample at that point, since in normal subjects the arterial curve has almost always flattened out at 10 minutes, and equilibrium between arterial and cerebral venous blood is approaching; lack of agreement indicates technical error, poorly-placed venous needle, or unsteady gas administration, any of which would invalidate the observation. In our experience, the agreement in each instance has been close, the greatest variation being 0.44 volumes \% nitrous oxide in a subject with a relatively slow flow, and the average variation in 49 determinations being 0.24 volumes $\%$. The nitrous oxide mixture is always given in such excess that only an extremely gross leak could alter the determination. It is felt that this is probably of small import actually, for our figures have not varied in subsequent patients, on whom a self-retaining mask was used. The potential advantages of the integrated sample technique will be dealt with at the end of this section.

The blood samples were placed in ice immediately on being collected, the usual precautions having been taken to assure the absence of air bubbles. The $\mathrm{pH}$ of the integrated arterial sample was measured with a glass electrode by means of a Beckman $\mathrm{pH}$ meter immediately after each blood flow. 
The subject was allowed to remain supine for 20 to 25 minutes following the first blood flow; then the table was tilted so that the subject stood erect at an angle of $65^{\circ}$ to the horizontal. In this position the weight was supported partially by the legs and partially by leaning against the table. When the subject's blood pressure and pulse stabilized, and he showed no signs of ensuing syncope, the same procedure of gas inhalation and blood withdrawal was performed. The patient was then put supine, and if he was not uncomfortable or tired, a third flow was done after a wait of 25 minutes.

The arterial pressure was measured by auscultation every two minutes during the supine flows and every minute during the erect. In both positions measurement was always done with the subject's arm held at approximate heart level. From these readings average mean pressures were computed by adding one-third of the pulse pressure to the diastolic pressure. This method is in use in other laboratories, and observations here have shown that the mean pressure calculated in this way is about the same as that measured by the Hamilton manometer. In 91 observations in this laboratory the mean pressure calculated by adding one-third of the pulse pressure to the diastolic pressure on the manometer tracings varied on the average of $3 \mathrm{~mm}$. $\mathrm{Hg}$ from the mean pressure calculated by the planimeter method. In order to have altered the accuracy of our comparisons of cerebral vascular resistance in the supine and erect posture, the error in mean arterial pressure would have had to be in the neighborhood of $25 \mathrm{~mm}$. $\mathrm{Hg}$, and consistently so. The pulse rate was measured every two to three minutes. Internal jugular venous pressures were measured by means of a spinal fluid manometer; the zero point was considered to be the needle level.

Arterial and venous samples were drawn simultaneously before and after each flow for glucose determinations, which were done by Nelson's photometric adaptation of the Somogyi method (5). The average of the two A-V glucose differences for each flow is used as the result.

In seven instances, single samples, drawn before and after the flows, were analyzed for oxygen by the Van Slyke manometric method (6) and averaged. In all other instances, oxygen determinations were made on the integrated blood samples by means of the Beckman spectrophotometer, using the method described by Hickam and Frayser (7).

The blood samples were analyzed for nitrous oxide by Kety's modification (2) of the original method of Orcutt and Waters (8). Here again certain modifications were made to suit our needs. The determinations were done on two different machines by two technicians, serving as checks on each other. The results were discarded if the calculated cerebral blood flows from the two machines did not agree within $10 \%$. In all but three instances the flows agreed within $7 \%$. Five $\mathrm{ml}$. blood samples were used in the analyses on the integrated arterial and venous samples. This was done in order to give a larger volume of gas and thus render the. difference of the manometer readings between the arterial and venous samples 2.5 times as great as with $2 \mathrm{ml}$. samples, and accordingly reduce the percentage error of the individual determinations. The mean arterio-venous nitrous oxide difference must be determined carefully, for a variation in this difference of 0.01 volumes $\%$ is equivalent to a variation of 0.09 volumes $\%$ in the final venous nitrous oxide sample. Samples of internal jugular blood, drawn immediately before each flow, were used for the blank determination. The difference between the blank samples on the same individual were negligible; it never varied more than 0.25 volumes $\%$. A sample determination is as follows:

Blank $=1.23$ volumes $\%$,

Integrated arterial sample $=5.34$ volumes $\%$,

Integrated venous sample $=4.53$ volumes $\%$,

Mean arterio-venous nitrous oxide difference for 10 min. $=0.81$ volumes $\%$,

Single venous nitrous oxide sample at $10 \mathrm{~min} .\left(V_{t}\right)=$ 5.05 volumes $\%$,

Single arterial nitrous oxide sample at $10 \mathrm{~min} .\left(A_{t}\right)=$ 5.19 volumes $\%$.

The cerebral blood flow can be calculated simply from these data:

$$
\mathrm{CBF}=\frac{5.05}{0.81 \times 10} \times 100=62 \mathrm{ml} . / \mathrm{min} . / 100 \mathrm{gm} . \text { brain. }
$$

The factor 100 is to convert the answer to units of per $100 \mathrm{gm}$. of brain, to be consistent with other data in the literature. The factor 10 converts the mean arteriovenous nitrous oxide difference per unit time (one minute) into the total mean arterio-venous nitrous oxide difference for the entire 10 minute period. The denominator is thus equivalent to Kety's expression $\int_{0}^{10}(A-V) d t$. In 49 complete cerebral blood flow analyses done by two technicians on different Van Slyke machines, on normal supine subjects, the following mean figures were obtained for the integral parts of the formula : $\int_{0}{ }^{10}(A-V) d t=7.11$ volumes per cent; $V_{t}=4.68 ; A_{t}=4.92$ with standard errors of $0.30,0.05$, and 0.09 respectively.

In this study the direct measurement of the mean arterio-venous nitrous oxide difference has the following advantages over the calculations of the mean difference from five separate samples: (1) Since only five Van Slyke analyses (and checks) are required for each blood flow (11 analyses [and checks] are required for the original method), several blood flows can be done the same day without straining the laboratory facilities. (2) It seemed more accurate to allow the body to integrate the samples than to draw curves through individual points. (3) Smaller quantities of blood can be used if necessary.

It is important to keep in mind that the nitrous oxide method measures only the mean cerebral blood flow over the 10 minute period of gas inhalation. Results obtained when the flow might be changing must be interpreted in that light; otherwise erroneous conclusions may be made. For example, if a subject had an abnormally rapid blood flow during the first five minutes of the observation, the nitrous oxide content of the cerebral 
venous blood may have reached or approached equilibrium with the nitrous oxide concentration of the brain at five minutes rather than 10 minutes, so that even if the blood flow fell to a very low level during the second five minutes, the analyses of the bloods would show a small mean arterio-venous nitrous oxide difference, and the flow would be calculated as being rapid. In studies on erect subjects, it is possible that the cerebral blood flow was falling progressively during the entire time, in which case an accurate mean flow for that period could be calculated. If, however, the flow was stable for the first six to eight minutes, and then fell rapidly during the last two to four minutes, the recorded blood flow would be calculated falsely high. It would seem, therefore, that if there is a mistake in our comparison of the supine and erect flows, it is that the average flow in the erect posture was actually lower than we have recorded it, and that the difference between supine and erect flows is even greater than our figures indicate. This can be checked by drawing cerebral arterio-venous oxygen differences before and after the flow, which we did in five instances, as mentioned in the results. If the flow falls progressively the integrated arterio-venous oxygen difference will be equal to the average of those drawn before and after. In our five subjects this was true. The formulae for the calculation of various metabolic functions discussed in this paper are given below:

Cerebral $\mathrm{O}_{2}$ consumption $(\mathrm{CMR} \mathrm{O})=\mathrm{CBF} \times \frac{\mathrm{A}-\mathrm{VO}_{2}}{100}$ in $\mathrm{ml} . \mathrm{O}_{2} / \mathrm{min} . / 100 \mathrm{gm}$. brain.
Cerebral glucose consumption $(\mathrm{CMR}$ gl.) $=\mathrm{CBF}$ $X \frac{A-V \text { glucose }}{100}$ in mgm. glucose $/ \mathrm{min} . / 100 \mathrm{gm}$. brain.

Cerebral vascular resistance

$$
(\mathrm{CVR})=\frac{\text { mean arterial pressure }}{\mathrm{CBF}}
$$

in $\mathrm{mm}$. $\mathrm{Hg} / \mathrm{ml}$. blood $/ 100 \mathrm{gm}$. brain $/ \mathrm{min}$.

\section{RESULTS}

Normal Values. The essential data are given in detail in Tables I and II. The cerebral blood flows supine varied from 50 to $103 \mathrm{ml} . / \mathrm{min} . / 100 \mathrm{gm}$. brain. Our mean figure for cerebral blood flow is $65 \mathrm{ml} . / \mathrm{min} . / 100 \mathrm{gm}$. brain (standard error 2.1) ; this is a significant difference statistically from the mean of 54 (standard error 2.1) reported by Kety (2), as indicated by the small standard errors of the two groups. The reasons for this difference are not clear: The average age of the subjects or differences in the techniques in the two laboratories may be responsible. The cerebral arterio-venous oxygen differences supine varied from 4.4 to 7.6 volumes $\%$ with a mean of 6.02 ; the mean reported by Kety is 6.3. The cerebral oxygen utilization ranged from 3.1 to $5.2 \mathrm{ml}$.

TABLE I

Cerebral metabolic functions in normal individuals in the supine and erect postures

\begin{tabular}{|c|c|c|c|c|c|c|c|c|c|c|c|}
\hline Subject & Age & $\begin{array}{c}\text { Surface } \\
\text { area }\end{array}$ & $\begin{array}{c}\text { Average } \\
\text { pulse rate }\end{array}$ & $\begin{array}{l}\text { Angle } \\
\text { tilted }\end{array}$ & $\begin{array}{c}\text { Apprehen- } \\
\text { sion }\end{array}$ & \multicolumn{3}{|c|}{$\begin{array}{l}\text { Cerebral blood flow } \\
\text { ml. } / \mathrm{min} . / 100 \mathrm{gm} . \text { brain }\end{array}$} & \multicolumn{3}{|c|}{$\begin{array}{l}\mathrm{A}-\mathrm{V}_{2} \mathrm{O}_{2} \text { diff. } \\
\text { vol. \% }\end{array}$} \\
\hline $\begin{array}{l}\text { J. G. } \\
\text { R. K. } \\
\text { J. C. } \\
\text { L. S. } \\
\text { R. M. } \\
\text { H. D. } \\
\text { D. M. } \\
\text { G. C. } \\
\text { J. C. } \\
\text { D. D. } \\
\text { P. S. } \\
\text { W. B. } \\
\text { J. T. } \\
\text { J. R. } \\
\text { J. S. } \\
\text { J H. } \\
\text { T. C. } \\
\text { W. Mc. } \\
\text { D. M. } \\
\text { R. H. }\end{array}$ & $\begin{array}{l}27 \\
24 \\
24 \\
24 \\
29 \\
27 \\
31 \\
23 \\
25 \\
22 \\
22 \\
27 \\
26 \\
23 \\
26 \\
28 \\
21 \\
19 \\
18 \\
36\end{array}$ & $\begin{array}{l}\text { sq. } M . \\
1.92 \\
1.89 \\
2.01 \\
1.80 \\
1.81 \\
1.82 \\
1.98 \\
1.86 \\
2.00 \\
2.24 \\
1.73 \\
2.14 \\
2.03 \\
1.93 \\
1.72 \\
1.89 \\
2.04 \\
1.69 \\
2.19 \\
1.86\end{array}$ & $\begin{array}{r}90 \\
70 \\
60 \\
75 \\
68 \\
76 \\
74 \\
64 \\
76 \\
60 \\
86 \\
72 \\
80 \\
60 \\
72 \\
64 \\
73 \\
100 \\
60 \\
70\end{array}$ & $\begin{array}{c}\text { degrees } \\
\\
65^{\circ} \\
65^{\circ} \\
65^{\circ} \\
65^{\circ} \\
65^{\circ} \\
65^{\circ} \\
45^{\circ} \\
50^{\circ} \\
40^{\circ} \\
45^{\circ} \\
65^{\circ} \\
65^{\circ} \\
65^{\circ} \\
50^{\circ}\end{array}$ & $\begin{array}{l}0-4+ \\
2+ \\
3+ \\
0 \\
0 \\
0 \\
2+ \\
2+ \\
0 \\
1+ \\
0 \\
2+ \\
1+ \\
0 \\
0 \\
0 \\
0 \\
2+ \\
2+ \\
0 \\
0\end{array}$ & $\begin{array}{c}\text { Sup. } \\
103 \\
50 \\
64 \\
78 \\
62 \\
61 \\
52 \\
65 \\
66 \\
63 \\
62 \\
68 \\
61 \\
97 \\
54 \\
65 \\
58 \\
55 \\
62 \\
56\end{array}$ & $\begin{array}{l}51 \\
53 \\
48 \\
40 \\
\\
56 \\
53 \\
42 \\
45 \\
81 \\
42 \\
57 \\
51\end{array}$ & $\begin{array}{l}\text { Sup. } \\
93 \\
\\
65 \\
56 \\
59 \\
\\
71 \\
\\
58 \\
59 \\
54 \\
56 \\
78 \\
63 \\
61\end{array}$ & $\begin{array}{l}\text { Sup. } \\
4.37^{*} \\
7.23^{*} \\
7.00^{*} \\
5.53 \\
\\
5.85 \\
5.91 \\
6.05 \\
5.08 \\
5.13 \\
5.99 \\
6.07 \\
6.33 \\
5.09 \\
5.75 \\
5.43 \\
6.74 \\
7.60^{*} \\
6.30^{*} \\
6.70^{*}\end{array}$ & $\begin{array}{l}\text { Er. } \\
\\
6.33^{*} \\
7.01 \\
8.83^{*} \\
7.83 \\
9.78 \\
6.66 \\
6.41^{*} \\
6.13 \\
7.20 \\
9.81 \\
7.43 \\
5.35 \\
6.65 \\
6.12 \\
9.37\end{array}$ & $\begin{array}{c}\text { Sup. } \\
4.63^{*} \\
\\
6.34^{*} \\
5.42 \\
8.84^{*} \\
7.19^{*} \\
\\
6.18 \\
5.10 \\
5.68 \\
5.95 \\
6.25 \\
4.80 \\
4.95 \\
5.67 \\
7.64\end{array}$ \\
\hline Mean & & & & & & 64.9 & 51.6 & 64.4 & 6.01 & 7.39 & 5.98 \\
\hline
\end{tabular}

Sup. = Supine.

Er. = Erect.

* These figures are the averages of $\mathrm{O}_{2}$ determinations on two individual samples, one drawn before the blood flow and the other at the end of the flow. All others are determinations on integrated samples, collected throughout the procedure, as described in the text. 
TABLE I-Continued

\begin{tabular}{|c|c|c|c|c|c|c|c|c|c|c|c|c|c|c|c|}
\hline $\begin{array}{l}\text { Subject } \\
\text { J. G. } \\
\text { R. K. }\end{array}$ & \multicolumn{3}{|c|}{ A-V glucose diff. } & \multicolumn{3}{|c|}{$\begin{array}{c}\text { Cerebral } \mathrm{O}_{2} \text { utilization } \\
\text { ml. } \mathrm{O}_{2} / \mathrm{min.} / \\
100 \mathrm{gm} . \text { brain }\end{array}$} & \multicolumn{3}{|c|}{$\begin{array}{l}\text { Cerebral glucose } \\
\text { utilization } \\
m g \text {. glucose/min. } \\
100 \text { gm. brain. }\end{array}$} & \multicolumn{3}{|c|}{$\begin{array}{l}\text { Effective mean cerebral } \\
\text { arterial pressure } \\
m m . \mathbf{H g}\end{array}$} & \multicolumn{3}{|c|}{$\begin{array}{l}\text { Cerebral vascular } \\
\text { resistance } \\
\text { mm. Hg/ml. blood } / \\
100 \mathrm{gm} \text {. brain } / \text { min. }\end{array}$} \\
\hline $\begin{array}{l}\text { J. G. } \\
\text { R. K. } \\
\text { J. C. } \\
\text { L. S. } \\
\text { R. M. } \\
\text { H. D. } \\
\text { D. M. } \\
\text { G. C. } \\
\text { J. C. } \\
\text { D. D. } \\
\text { P.S. } \\
\text { W. B. } \\
\text { J. T. } \\
\text { J. R. } \\
\text { J.S. } \\
\text { J. H. } \\
\text { T. C. } \\
\text { W. Mc. } \\
\text { D. M. } \\
\text { R. H. }\end{array}$ & $\begin{array}{c}\text { Sup. } \\
6 \\
10 \\
9 \\
9 \\
14 \\
9 \\
11 \\
12 \\
8 \\
13 \\
12 \\
9 \\
7 \\
12 \\
9 \\
11 \\
7 \\
9\end{array}$ & $\begin{array}{r}11 \\
12 \\
8 \\
7 \\
11 \\
7 \\
13 \\
13 \\
14 \\
8 \\
11 \\
9 \\
11 \\
14\end{array}$ & $\begin{array}{c}\text { Sup. } \\
8 \\
\\
9 \\
7 \\
13 \\
11 \\
11 \\
8 \\
16 \\
10 \\
10 \\
7 \\
8 \\
11 \\
12\end{array}$ & $\begin{array}{l}\text { Sup. } \\
4.50 \\
3.62 \\
4.48 \\
4.31 \\
3.57 \\
3.08 \\
3.93 \\
3.35 \\
3.33 \\
3.71 \\
4.12 \\
3.86 \\
4.93 \\
3.11 \\
3.53 \\
3.91 \\
4.18 \\
3.78 \\
3.74\end{array}$ & $\begin{array}{l}3.43 \\
3.82 \\
4.12 \\
3.35 \\
4.33 \\
2.80 \\
3.49 \\
4.72\end{array}$ & $\begin{array}{l}4.32 \\
3.06 \\
3.35 \\
3.21 \\
3.50 \\
3.75 \\
3.12 \\
3.46\end{array}$ & $\begin{array}{l}\text { Sup. } \\
6.18 \\
5.00 \\
5.75 \\
7.00 \\
8.54 \\
4.68 \\
7.15 \\
7.92 \\
5.20 \\
8.06 \\
8.16 \\
4.27 \\
6.30 \\
6.75 \\
5.85 \\
6.10 \\
4.34 \\
5.60\end{array}$ & $\begin{array}{l}6.72 \\
6.90 \\
5.90 \\
3.60 \\
8.50 \\
4.00 \\
6.27 \\
7.15\end{array}$ & $\begin{array}{l}7.58 \\
4.62 \\
9.46 \\
5.92 \\
5.60 \\
5.08 \\
4.72 \\
6.71\end{array}$ & \begin{tabular}{|c|} 
Sup. \\
94 \\
86 \\
86 \\
87 \\
70 \\
82 \\
100 \\
73 \\
81 \\
91 \\
72 \\
90 \\
92 \\
85 \\
78 \\
80 \\
84 \\
92 \\
90 \\
70
\end{tabular} & $\begin{array}{l}\text { Er. } \\
\\
56 \\
46 \\
49 \\
52 \\
50 \\
46 \\
\\
61 \\
51 \\
60 \\
73 \\
62 \\
57 \\
59 \\
50\end{array}$ & $\begin{array}{l}74 \\
89 \\
75 \\
79 \\
92 \\
84 \\
77 \\
79 \\
87\end{array}$ & $\begin{array}{l}\text { Sup. } \\
0.91 \\
1.70 \\
1.34 \\
1.11 \\
1.13 \\
1.34 \\
1.93 \\
1.12 \\
1.16 \\
1.40 \\
1.16 \\
1.32 \\
1.51 \\
0.88 \\
1.44 \\
1.23 \\
1.45 \\
1.67 \\
1.45 \\
1.25\end{array}$ & $\begin{array}{l}1.09 \\
0.96 \\
1.43 \\
1.62 \\
0.77 \\
1.35 \\
1.03 \\
0.98\end{array}$ & $\begin{array}{l}1.04 \\
1.48 \\
1.27 \\
1.46 \\
1.64 \\
1.07 \\
1.22 \\
1.29\end{array}$ \\
\hline Mean & 9.6 & 10.6 & 10.0 & 3.84 & 3.83 & 3.69 & 6.27 & 5.61 & 6.08 & 84.5 & 55.1 & 81.2 & 1.33 & 1.12 & 1.27 \\
\hline
\end{tabular}

oxygen $/ \mathrm{min} . / 100 \mathrm{gm}$. brain. The mean figure for cerebral oxygen utilization obtained here was $3.8 \mathrm{ml}$. oxygen $/ \mathrm{min} . / 100 \mathrm{gm}$. brain, while that obtained in Kety's lab was 3.3. The difference is due to the difference in the figures for cerebral blood flow. The other values are quite similar to those reported from other laboratories (9-12).

The cerebral vascular resistance in the supine position ranged from 0.86 to 1.93 , with a mean of 1.31. The cerebral vascular resistance has been given as the quotient of the $\frac{\text { mean arterial pressure }}{\text { cerebral blood flow }}$, disregarding the internal jugular pressure. Only preliminary observations on internal jugular pressure were made; further studies are now in progress and will be reported at a later date. The available measurements indicate that the average fall in internal jugular pressure on assuming the erect posture is $60 \mathrm{~mm}$. water.

The cerebral arterio-venous glucose differences supine ranged from 6 to $16 \mathrm{mgm}$. \%, and the cerebral glucose utilizations varied from 3.9 to 9.5 mgm. glucose $/ 100 \mathrm{gm}$. brain $/ \mathrm{min}$. The ratios of cerebral arterio-venous glucose difference to ar-

TABLE II

Cerebral metabolic functions in normal persons in the supine posture

\begin{tabular}{|c|c|c|c|c|c|}
\hline & $\stackrel{\text { No. of }}{\text { determinations }}$ & Mean & Std. dev.* & Std. errort & $\begin{array}{l}\text { Coeff. of } \\
\text { variation }\end{array}$ \\
\hline 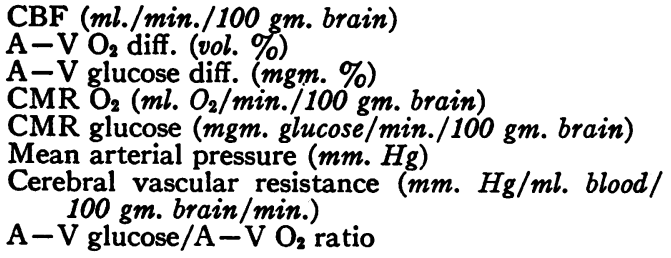 & $\begin{array}{l}32 \\
33 \\
32 \\
31 \\
29 \\
33 \\
32 \\
31\end{array}$ & $\begin{array}{l}64.7 \\
6.02 \\
9.94 \\
3.79 \\
6.20 \\
83 \\
1.31 \\
1.67\end{array}$ & $\begin{array}{l}12.1 \\
0.81 \\
2.39 \\
0.55 \\
1.41 \\
8.32 \\
0.24 \\
0.353\end{array}$ & $\begin{array}{l}2.14 \\
0.14 \\
0.42 \\
0.09 \\
0.26 \\
1.45 \\
\\
0.04 \\
0.06\end{array}$ & $\begin{array}{l}19 \% \\
13 \% \\
24 \% \\
13 \% \\
22 \% \\
10 \% \\
18 \% \\
21 \%\end{array}$ \\
\hline
\end{tabular}

* Standard deviation $=s=\sqrt{\frac{\Sigma x^{2}-\frac{(\Sigma x)^{2}}{n}}{n-1}}$.

$\dagger$ Standard error $=\frac{s}{\sqrt{n}}$. 
TABLE III

Relationship of cerebral blood flow to apprehension

\begin{tabular}{l|c|c|c}
\hline \hline Subject & $\begin{array}{c}\text { Apprehensive } \\
\text { Cerebral blood flow }\end{array}$ & Subject & $\begin{array}{c}\text { Not apprehensive } \\
\text { Cerebral blood flow }\end{array}$ \\
\cline { 1 - 3 } $\begin{array}{c}\text { ml./min./sq. M. } \\
\text { body surface }\end{array}$ & & $\begin{array}{c}\text { ml./min./sq. M. } \\
\text { body surface }\end{array}$ \\
J. G. & 700 & J. C. & 453 \\
R. K. & 370 & L. S. & 521 \\
H. D. & 470 & R. J. & 472 \\
D. M. & 368 & G. C. & 512 \\
P. A. & 494 & D. D. & 382 \\
W. B. & 399 & J. T. & 407 \\
W. McL. & 452 & J. R. & 638 \\
J. C. & 462 & J. S. & 480 \\
T. C. & 398 & J. H. & 467 \\
& & D. M. & 397 \\
& & R. H. & 422 \\
Mean & 457 & Mean & 468 \\
\hline
\end{tabular}

terio-venous oxygen difference varied from 1.10 to 2.46 , a mean of 1.67 . The variations are probably related primarily to the method of glucose determination. It is interesting that, although the expected ratio is 1.34 , the figure obtained in this study corresponds closely to that of 1.62 obtained by Gibbs et al. (12) in 50 determinations on 25 schizophrenic and epileptic patients. There is no evidence for altered cerebral metabolism in such subjects (13). There is no indication that inhalation of 15 per cent nitrous oxide alters this figure. Since our present knowledge of normal brain metabolism is incomplete, as recent studies (14) have demonstrated, it may well be that the ratio of 1.34 , anticipated from the chemical equation of the complete breakdown of glucose to carbon dioxide and water is inaccurate. Though oxygen: carbon dioxide ratios have indicated a cerebral R.Q. of about 1.00 , it is entirely possible that other mechanisms, such as the partial oxidation of glucose to pyruvic and lactic acids, and the conversion of carbohydrate to fat, may fortuitously place this figure at 1.00 .

Apprehension. The effect of apprehension on cerebral blood flow is summarized in Table III. The criteria used to determine apprehension were: (1) clinical observations, (2) rapid pulse, and (3) elevated systolic pressure. Those subjects who were considered to be apprehensive had a range of cerebral blood flow from 370 to $700 \mathrm{ml} . / \mathrm{min} . /$ sq.M. body surface; those who were not considered to be apprehensive had a range of 382 to 638. There is no significant difference between the means of these two groups.

Posture. The effects of changing the subjects from the supine to the erect position are summarized in Table IV. The mean cerebral arterial pressure in the erect position was calculated by subtracting from the mean erect brachial arterial blood pressure the vertical distance in $\mathrm{mm}$. $\mathrm{Hg}$ from the second rib to the mid-cerebrum. This can easily be calculated since the patient's angle to the horizontal plane is known. Although we did not make direct measurements of the carotid pressure in the erect position, it is felt that the application of hydrostatic laws to the circulation justify this assumption. Measurements of common carotid arterial pressure with the subjects in a vertical head-up position by Loman (15) showed a mean fall of $20 \mathrm{~mm}$. $\mathrm{Hg}$ in 23 observations. This figure closely corresponds with our calculated one of $22 \mathrm{~mm}$. $\mathrm{Hg}$ fall, if it is considered that our subjects were only tilted to $65^{\circ}$ and that the mid-cerebrum is about $15 \mathrm{~cm}$. cephalad to the point at which Loman and his group were measuring.

The cerebral blood flow in the erect position varied from 40 to $81 \mathrm{ml} . / \mathrm{min} . / 100 \mathrm{gm}$. brain, with

TABLE IV

Alterations of cerebral metabolic functions on changing from the supine to the erect posture

\begin{tabular}{|c|c|c|c|c|c|}
\hline & $\begin{array}{c}\text { No. of } \\
\text { Comparisons }\end{array}$ & \multicolumn{2}{|c|}{ Mean } & P value* & Change \\
\hline 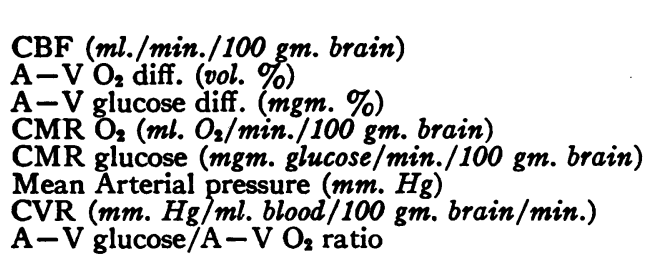 & $\begin{array}{l}13 \\
13 \\
14 \\
13 \\
11 \\
14 \\
12 \\
14\end{array}$ & $\begin{array}{c}\text { Supine } \\
65.1 \\
6.00 \\
10.10 \\
3.84 \\
6.40 \\
84.0 \\
1.33 \\
1.76\end{array}$ & $\begin{array}{c}\text { Erect } \\
51.6 \\
7.39 \\
10.60 \\
3.83 \\
5.61 \\
55.0 \\
1.12 \\
1.54\end{array}$ & $\begin{array}{r}<0.01 \\
<0.01 \\
>0.5 \\
\\
0.2 \\
<0.01 \\
\quad 0.17\end{array}$ & $\begin{array}{l}\% \\
-21 \\
+23 \\
\\
-34 \\
-16\end{array}$ \\
\hline
\end{tabular}

* $P$ value of 0.02 or less is considered significant. 
a mean of 52 . This represented a $21 \%$ fall in cerebral blood flow over the supine position. This is a highly significant change statistically. Observations reported by Shenkin et al. (16) using the nitrous oxide technique showed no fall in cerebral blood flow in five normal persons tilted head-up $20^{\circ}$ from the horizontal.

The cerebral arterio-venous oxygen difference in the erect position ranged from 5.4 to 9.8 volumes $\%$, with a mean of 7.4 volumes $\%$. This represents an increase of $23 \%$ over the supine position, a highly significant change statistically.

The cerebral oxygen utilization, cerebral arterio-venous glucose difference, cerebral glucose utilization, and $\frac{\mathrm{A}-\mathrm{V} \text { glucose }}{\mathrm{A}-\mathrm{V} \text { oxygen }}$ ratio did not change significantly.

The effective mean cerebral arterial pressure fell an average of $34 \%$ from the supine to the erect position. The vertical distance from the second rib to the mid-cerebrum in our subjects averaged $22 \mathrm{~mm} . \mathrm{Hg}$; the average fall in mean auscultatory pressure on standing erect was $7 \mathrm{~mm}$. Hg. The cerebral vascular resistance in the erect position ranged from 0.90 to 1.62 , with a mean of 1.12 . This represented an average fall of $16 \%$ from the supine position, a highly significant change statistically.

Because other studies have pointed out the fall in cerebral blood flow associated with over-ventilation (17) the arterial blood $\mathrm{pH}$ was measured after each blood flow. There was no difference between the $\mathrm{pH}$ in the supine and that in the erect posture, indicating that the observed alterations in cerebral metabolism during posture change were not related to changes in respiration, insofar as these changes could be measured by the blood $\mathrm{pH}$.

In five instances, cerebral arterio-venous oxygen differences were measured when the subject was first tilted erect and again just before he was put supine, as well as from the integrated samples. In every instance the arterio-venous oxygen difference increased during the period of the flow, indicating the value of the integrated samples for accurate calculation of mean cerebral oxygen utilization.

\section{COMMENT}

The values for the various normal metabolic functions of the brain vary over a wide range from person to person, and these variations are not altered significantly by relating the values to the surface area of the patient. Statistical analysis of available anatomical data of brain weight and surface area (18) reveals that the correlation coefficient of these figures is between 0.45 and 0.50 , roughly in the range of correlation of other biological variables. The variations from individual to individual of the values for cerebral metabolic functions seem to be due to two causes: (a) much of the variation is probably real, just as there is known to be individual variations in other physiologic functions, and $(b)$ technical errors are probably partially responsible, as are minor anomalies in the anatomy of the internal jugular circulation. There seems to be no way of predicting at present whether contamination of the jugular blood by a vein draining the subcutaneous and deep tissues of the face would erroneously raise or lower the calculated cerebral blood flow. If arterio-venous shunts in the skin were open and contributed to the contamination, the figure would be falsely high; if the contaminating vein drained only areas of fat, the figure might be falsely low. Studies to clarify this problem are in progress.

The accumulated data on normal individuals seem to indicate that the rate of cerebral oxygen utilization during the time of the experiment is a fairly constant figure in any given person, and that, lacking clinical signs of cerebral dysfunction, the cerebral arterio-venous oxygen difference increases as the rate of blood flow falls. The alterations in cerebral blood flow and cerebral arteriovenous oxygen difference on assuming the erect posture are of similar magnitude $(-21 \%$ and + $23 \%$ respectively) but in opposite directions, so that the rate of cerebral oxygen utilization remains the same. The same relationship would be expected to hold for cerebral blood flow and arteriovenous glucose difference, but technical inaccuracies involved in performing the analyses for blood glucose obviate any definite conclusions on this score at present.

The ability to maintain a stable rate of oxygen utilization under most conditions exists in the liver (19) as well as the brain. The kidney, on the other hand, does not behave similarly, but maintains a fairly constant arterio-venous oxygen difference in the face of a considerable fall in blood flow (20). Under certain conditions of duress, the 
brain also behaves differently; Kety and coworkers have shown that in insulin hypoglycemia the cerebral blood flow remains stable, while the cerebral arterio-venous oxygen and arterio-venous glucose differences fall strikingly, giving lowered rates of cerebral oxygen and glucose consumption (21).

We have compared this group of normals with a group of similar individuals studied by Stead et al. (22), on whom the cardiac index in the resting state was determined. It seemed fair to make this comparison because of these reasons: (a) The subjects were, in both instances, mainly normal medical students and were studied under similar conditions; $(b)$ The average surface area in the two groups was almost identical (1.87 sq.M. in Stead's study and 1.92 sq.M. in this study); the size of the groups was also the same; and (c) the addition of another procedure, such as the measurement of the cardiac output, to that of measuring the cerebral metabolism, would almost necessarily obviate the existence of a basal state in the subjects. Table V summarizes these com-

TABLE $v$

Relationship of cerebral blood flow and cerebral $\mathrm{O}_{2}$ consumption to cardiac output and total $\mathrm{O}_{2}$ consumption

Cardiac index $(1 / \min . / \text { sq. M. })^{*}$

Cerebral blood flow (1/min./sq. $M$.)

$\%$ Cardiac output to cerebral circulation

Total $\mathrm{O}_{2}$ consumption (ml./min./sq. M.)*

Cerebral $\mathrm{O}_{2}$ utilization (ml./min./sq. M.)

Cerebral $\mathrm{O}_{2}$ consumption as percentage of total $\mathrm{O}_{2}$ consumption

* Stead et al. (22); see text for explanation.

parisons. Our calculations were made on the basis of an average brain weight of $1400 \mathrm{gm}$. Since we were comparing two different groups, only comparisons of means could be made. The data indicate that approximately $14 \%$ of the cardiac output in the resting state is devoted to the cerebral circulation, whereas the cerebral oxygen consumption is about $22 \%$ of the total oxygen consumption of the body. If the figures given by Kety and Schmidt (17) for percentage of cardiac output devoted to cerebral circulation and cerebral oxygen consumption as percentage of total oxygen consumption are recalculated using 1.0 as the solubility coefficient of nitrous oxide between brain and blood, the resultant averages of $15 \%$ and $19 \%$ closely approximate our results. It should be pointed out that this agreement appears to be fortuitous, for their figures for cardiac output, measured by the ballistocardiogram, are moderately lower than those usually given in measurements done by the direct Fick principle.

The finding that the cerebral blood flow is not altered in apprehension is of considerable physiological interest. Although Table III includes only cerebral blood flow, no correlation was found between apprehension and any aspect of cerebral metabolic function measured in this study. The cardiac output increases about $40 \%$ during apprehension $(22,23)$; it would be interesting to know where the blood goes in this condition. Apparently it does not go to the brain, kidney, or skin.

Although our studies have not revealed a quantitative relationship between alterations in the arterial pressure and cerebral blood flow in the same person, there was a definite fall in cerebral blood flow with the fall in effective cerebral arterial pressure on standing. The significance of the fall in cerebral vascular resistance in the erect posture cannot be interpreted with available data. There are at least two possibilities: (a) The cerebral vessels may actually dilate in response to a fall in arterial pressure or in response to whatever stimuli result from standing erect. Direct observations of the pial vessels of the cat through a Forbes window have shown that a fall in arterial pressure is a strong stimulus for the production of pial vasodilatation (24). (b) The fall in cerebral vascular resistance may be the result of a decrease in pressure on the venous side of the capillaries, since blood in the internal jugular system must certainly run down-hill when the subject is erect.

\section{SUMMARY AND CONCLUSIONS}

1. The nitrous oxide method for measurement of cerebral blood flow was used in 33 observations on 20 normal young men in the supine posture. Modifications in the original method are described.

2. Normal figures are given for cerebral blood flow, cerebral arterio-venous oxygen difference, cerebral oxygen utilization, cerebral arteriovenous glucose difference, cerebral glucose utilization, and cerebral vascular resistance.

3. In normal, resting subjects $14 \%$ of the cardiac output is devoted to the cerebral circula- 
tion; $22 \%$ of the total oxygen consumption of the body is cerebral oxygen consumption. The significance of this is discussed.

4. Observations on apprehensive subjects revealed no difference in cerebral metabolic function from those who were not anxious.

5. Tilting normal subjects to the erect posture resulted in a $21 \%$ fall in cerebral blood flow, a $23 \%$ increase in cerebral arterio-venous oxygen difference, a $34 \%$ fall in effective cerebral arterial pressure, and a $16 \%$ fall in cerebral vascular resistance.

6. Cerebral oxygen utilization is a relatively constant figure in the normal person under ordinary stresses. Its buffer system is flexible, allowing the cerebral arterio-venous oxygen difference to compensate for relatively large changes in cerebral blood flow.

7. The fall in cerebral vascular resistance in the erect position may be the result of cerebral vascular dilatation or a decrease in pressure on the venous side of the cerebral capillaries.

\section{ACKNOWLEDGMENTS}

The authors are indebted to Dr. Seymour S. Kety and colleagues for instruction in the techniques utilized in this paper. These studies were done with the technical assistance of Mrs. Regina Spencer, Miss Frances Morgan, and Mrs. Louise Allen.

\section{BIBLIOGRAPHY}

1. Kety, S. S., and Schmidt, C. F., The determination of cerebral blood flow in man by the use of nitrous oxide in low concentrations. Am. J. Physiol., 1945, 143, 53.

2. Kety, S. S., and Schmidt, C. F., The nitrous oxide method for the quantitative determination of cerebral blood flow in man: theory, procedure, and normal values. J. Clin. Invest., 1948, 27, 476.

3. Myerson, A., Halloran, R. D., and Hirsch, H. L., Technique for obtaining blood from the internal jugular vein and internal carotid artery. Arch. Neurol. \& Psychiat., 1927, 17, 807.

4. Kety, S. S., Harmel, M. H., Broomell, H. T., and Rhode, C. B., The solubility of nitrous oxide in blood and brain. J. Biol. Chem., 1948, 173, 487.

5. Nelson, N., A photometric adaptation of the Somogyi method for the determination of glucose. J. Biol. Chem., 1944, 153, 375.

6. Van Slyke, D. D., and Neill, J. M., The determination of gases in blood and other solutions by vac- uum extraction and manometric measurement. J. Biol. Chem., 1924, 61, 523.

7. Hickam, J., and Frayser, R., Spectrophotometric determination of blood oxygen content. J. Biol. Chem., in press.

8. Orcutt, F. S., and Waters, R. M., A method for the determination of cyclopropane, ethylene, and nitrous oxide in the blood with the Van Slyke-Neill manometric apparatus. J. Biol. Chem., 1937, 117, 509.

9. Lennox, W. G., Constancy of the cerebral blood flow. Arch. Neurol. \& Psychiat., 1936, 36, 375.

10. Gibbs, E. L., Lennox, W. G., Nims, L. F., and Gibbs, F. A., Arterial and cerebral venous blood. Arterial-venous differences in man. J. Biol. Chem., 1942, 144, 325.

11. Gibbs, F. A., Maxwell, H., and Gibbs, E. L., Volume flow of blood through the human brain. Arch. Neurol. \& Psychiat., 1947, 57, 137.

12. Gibbs, E. L., Lennox, W. G., and Gibbs, F. A., Bilateral internal jugular blood: Comparison of arterio-venous difference, oxygen-dextrose ratios and respiratory quotients. Am. J. Psychiat., 1945, $102,184$.

13. Elliott, K. A. C., and Penfield, W., Respiration and glycolysis of focal epileptogenic human brain tissue. J. Neurophysiol., 1948, 11, 485.

14. Elliott, K. A. C., Metabolism of brain tissue slices and suspensions from various mammals. J. Neurophysiol., 1948, 11, 473.

15. Loman, J., Dameshek, W., Myerson, A., and Goldman, D., Effect of alterations in posture on the intra-arterial blood pressure in man. I. Pressure in the carotid, brachial, and femoral arteries in normal subjects. Arch. Neurol. \& Psych., 1936, 35, 1216.

16. Shenkin, H. A., Scheuerman, W. G., Spitz, E. B., and Groff, R. A., The effect of change of position upon the cerebral circulation of man. Am. J. Med. Sc., 1948, 216, 714.

17. Kety, S. S., and Schmidt, C. F., The effects of active and passive hyperventilation on cerebral blood flow, cerebral oxygen consumption, cardiac output, and blood pressure of normal young men. J. Clin. Invest., 1946, 25, 107.

18. Greenwood, M., Jr., and Brown, J. W., A second study of the weight, variability, and correlation of the human viscera. Biometrika, 1913, 9, 473.

19. Myers, J. D., The hepatic blood flow and splanchnic oxygen consumption of man-their estimation from urea production or bromsulphalein excretion during catheterization of the hepatic veins. J. Clin. Invest., 1947, 26, 1130.

20. Dole, V. P., Emerson, K., Jr., Phillips, R. A., Hamilton, P., and Van Slyke, D. D., The renal extrac- 
tion of oxygen in experimental shock. Am. J. Physiol., 1946, 145, 337.

21. Kety, S. S., Lukens, F. D. W., Woodford, R. B., Harmel, M. H., Freyhan, R. A., and Schmidt, C. F., The effect of insulin hypoglycemia and coma on human cerebral metabolism and blood flow. Federation Proc., 1948, 7, 64.

22. Stead, E. A., Jr., Warren, J. V., Merrill, A. J., and Brannon, E. S., The cardiac output in male subjects as measured by the technique of right atrial catheterization. Normal values with observations on the effect of anxiety and tilting. J. Clin. Invest., 1945, 24, 326.

23. Hickam, J. B., Cargill, W. H., and Golden, A., Cardiovascular reactions to emotional stimuli. Effect on the cardiac output, arteriovenous oxygen difference, arterial pressure, and peripheral resistance. J. Clin. Invest., 1948, 27, 290.

24. Fog, M., Reaction of the pial arteries to fall in blood pressure. Arch. Neurol. \& Psychiat., 1937, 37, 351. 